\title{
ABORDAGENS DE AVALIAÇÃO DE ATIVOS INTANGÍVEIS: UMA REVISÃO DA LITERATURA
}

\author{
INTANGIBLE ASSET EVALUATION APPROACHES: A LITERATURE REVIEW
}

\begin{abstract}
STEPHANIE KALYNKA ROCHA SILVEIRA
Mestranda em Contabilidade pela Universidade Federal de Santa Catarina. Atualmente é Coordenadora de Contabilidade na Fundação Educacional do Município de São José, Diretora Geral de Auditoria no Centro Universitário Municipal de São José e Professora no Centro Universitário Estácio Santa Catarina. Endereço: Fundação Educacional Municipal, Avenida Acioni Souza Filho / Praia Comprida / 88103790 / São José/SC | Brasil.

E-mail: stephaniekrocha@gmail.com
\end{abstract}

\section{DARCI SCHNORRENBERGER}

Doutor em Gestão de Negócios pela Universidade Federal de Santa Catarina. Atualmente é professor Associado do curso de Ciências Contábeis e do Programa de Pós-Graduação em Contabilidade da Universidade Federal de Santa Catarina. Endereço: Universidade Federal de Santa Catarina, Departamento de Ciências Contábeis, Campus-Trindade-CSE/CCN, Trindade / 88040-970 / Florianópolis/SC | Brasil.

E-mail: darcisc@gmail.com

\section{VALDIRENE GASPARETTO}

Doutora em Engenharia de Produção pela Universidade Federal de Santa Catarina. Professora da Universidade Federal de Santa Catarina, atuando no curso de graduação e no programa de pósgraduação. Endereço: Universidade Federal de Santa Catarina, Departamento de Ciências Contábeis, Campus-Trindade-CSE/CCN, Trindade | 88040-970 | Florianópolis/SC / Brasil.

E-mail: valdirenegasparetto@gmail.com

\section{ROGÉRIO JOÃO LUNKES}

Doutor em Engenharia de Produção pela Universidade Federal de Santa Catarina. Professor da Universidade Federal de Santa Catarina. Endereço: Universidade Federal de Santa Catarina, Departamento de Ciências Contábeis, Campus-Trindade-CSE/CCN, Trindade / 88040970 | Florianópolis/SC | Brasil.

E-mail: rogeriolunkes@hotmail.com

\section{RESUMO}

O objetivo deste estudo consiste em analisar as abordagens de avaliação de ativos intangíveis apresentadas na literatura nacional e internacional. Para tanto, fez-se uso de uma base filosófica construtivista e do Knowledge Development Process - Constructivist (ProKnow-C) como instrumento de intervenção para revisão da literatura. No levantamento realizado nas bases: (i) EBSCO; (ii) ProQuest; (iii) Scopus; (iv) Science Direct e (v) Spell encontrou-se o total de 1.672 artigos utilizando as palavras: Capital Intelectual ou Ativo Intangível e Organização em seu (i) título, (ii) resumo ou (iii) palavras-chave. A partir do aprimoramento da pesquisa com os critérios (i) exclusão de artigos repetidos/ redundantes; (ii) alinhamento dos artigos ao tema 
quanto ao título; (iii) reconhecimento científico dos artigos; (iv) alinhamento dos artigos ao tema quanto aos resumos e (v) disponibilidade dos artigos na íntegra, chegou-se a um Portfólio Bibliográfico (PB) composto de 28 artigos. Na análise desse $\mathrm{PB}$, identificou-se o total de 41 abordagens de avaliação de ativos intangíveis. Skandia Navigator foi a abordagem mais citada, totalizando $13 \%$ das citações. Constatou-se também as categorias e o enquadramento de cada abordagem, identificando-se que existem algumas lacunas de pesquisas envolvendo as abordagens de avaliação.

Palavras-chave: Ativos Intangíveis. Abordagens de avaliação. Categorias. Enquadramento.

\begin{abstract}
The aim of this study is to analyze the intangible asset evaluation approaches presented in national and international literature. Therefore, there was use of a philosophical basis constructivist and the Knowledge Development Process - Constructivist (ProKnow-C) as an intervention tool for literature review. This survey was carried out on the following basis: (i) EBSCO; (li) ProQuest; (lii) Scopus; (Iv) Science Direct; and (v) Spell, where it was met the total of 1,672 articles using the words: Intellectual Capital or Intangible Assets and Organization in their (i) titles, (ii) abstracts or (iii) keywords. From the research improvement using the criteria (i) exclusion of repeated / redundant articles; (li) alignment of articles to the subject as the title; (lii) scientific recognition of articles; (IV) alignment of articles to the subject as the abstracts; and ( $V$ ) availability of full articles, it was reached to a Bibliographical Portfolio (CP) consisting of 28 articles. By analyzing this PB, it was identified a total of 41 approaches to evaluation of intangible assets. Skandia Navigator was the most cited approach, totaling $13 \%$ of the citations. It was also found categories and the framing of each approach, identifying that there are some gaps in research involving the evaluation approaches.
\end{abstract}

Keywords: Intangible Assets. Assessment Approaches. Categories. Framework.

\title{
1INTRODUÇÃO
}

Uma das mudanças no cenário de atuação das empresas na era da informação e do conhecimento é o destaque dos ativos intangíveis como fonte de vantagem competitiva, e a efetiva gestão e aplicação desses ativos no auxílio de sua conversão em resultados (FRANCINI, 2002).

Os ativos intangíveis são destacados no cenário atual como aliados na busca da competitividade organizacional, no entanto, as empresas precisam identificá-los para utilizá-los estrategicamente. Diante do fato, constata-se a necessidade das organizações de recorrerem a abordagens sistemáticas de gerenciamento dos intangíveis (Roos \& Roos, 1997).

Pesquisas vêm sendo conduzidas a fim de definir um caminho confiável e prático para avaliar os intangíveis de uma empresa. Vários modelos de avaliação foram desenvolvidos, embora ainda haja problemas a resolver (Joia, 2001).

Muitas tentativas de desenvolver formas de abordagens capazes de avaliar os intangíveis foram encontradas na literatura. Portanto, o estudo teve o propósito de identificar as abordagens mais citadas na literatura e classificá-las quanto às suas categorias e enquadramento. Dentro desse contexto surge o seguinte questionamento: quais as categorias e enquadramento das abordagens de avaliação dos intangíveis mais citadas na literatura?

Com isso, o objetivo deste estudo consiste em analisar as abordagens de avaliação de ativos intangíveis apresentadas na literatura nacional e internacional.

A justificativa para a realização desta pesquisa dá-se pela contribuição esperada para a comunidade científica e para os gestores, no sentido de destacar as abordagens de avaliação mais citadas na literatura, que auxiliam na mensuração e administração dos intangíveis, levantando suas categorias e enquadramento.

O presente artigo se estrutura em cinco seções. Primeiramente esta, de caráter introdutório. Em seguida, apresenta-se a revisão da literatura e, na terceira seção, aborda-se a 
metodologia da pesquisa. Na quarta seção apresentam-se os resultados e, por fim, as considerações finais, na quinta seção, seguida das referências utilizadas.

\section{REFERENCIAL TEÓRICO}

A estrutura dos investimentos feitos pelas empresas tem mudado durante as últimas décadas expressando a transição da economia industrial para uma economia baseada em conhecimento (Zéghal \& Maalouol, 2011). Com a transformação da economia, além dos investimentos em capital tangível, tais como materiais, máquinas e equipamentos, os investimentos em capital intangível, como marcas, clientes e relações com fornecedores, knowhow, redes e patentes, tornaram-se cada vez mais relevantes (Zéghal \& Maalouol, 2011; Lev, 2001; Santos, 2002; Santos \& Schmidt, 2003; Wernke \& Bornia, 2003; Kayo, Kimura, Basso \& Krauter, 2008).

Destaca-se que essa relevância de investimentos em intangíveis foi provocada pela (i) globalização do comércio e desregulamentação de setores-chave da economia e (ii) pelo advento das tecnologias de informação, o quais, passaram a considerar componentes intangíveis como impulsionadores do valor dos negócios (Lev, 2001, Santos, 2002, Santos \& Schmidt, 2003, Wernke \& Bornia, 2003, Kayo et al., 2008, García-Meca \& Martínez, 2007).

O termo intangível abrange várias noções complementares, que não são diferentes na forma e conteúdo, tais como investimentos intangíveis, ativos intangíveis e capital intangível (Zéghal \& Maalouol, 2011). Além disso, a revisão da literatura destaca vários outros conceitos que podem ser considerados sinônimos do termo recursos intangíveis, ou seja, capital intangível, capital intelectual, capital imaterial, capital de conhecimento, bens intangíveis, conforme demonstrado na Tabela 1.

Tabela 1

Termos utilizados para intangíveis

\begin{tabular}{l|c|c}
\hline \multicolumn{1}{c|}{ Autores } & Ano & Termo \\
\hline Vergauwen; Alem & 2005 & Capital Intelectual \\
\hline Oliveira; Rodrigues; Craig & 2006 & Intangível/Capital Intelectual \\
\hline Martínez; García-Meca & 2007 & Capital Intelectual/ Intangível/ Bens Intangíveis \\
\hline Macagnan & 2009 & Recursos intangíveis \\
\hline Oliveira; Rodrigues; Craig & 2010 & Capital intelectual \\
\hline Zéghal; Maaloul & 2011 & Investimento Intangível; capital intelectual, capital imaterial, capital de \\
& & conhecimento \\
\hline Hidalgo; García-Meca; Martínez & 2011 & Capital Intelectual \\
\hline Kang; Gray & 2011 & Ativo intangível \\
\hline Kumar & 2013 & Ativos Intangíveis \\
\hline Fontana; Macagnan & 2013 & Ativos Intangíveis \\
\hline
\end{tabular}

Nota. Fonte: Vergauwen e Alem (2005); Oliveira, Rodrigues e Craig (2006); García-Meca e Martínez (2007); Macagnan (2009); Oliveira, Rodrigues e Craig (2010); Zéghal e Maaloul (2011); Hidalgo, García-Meca e Martínez (2011); Kang; Gray (2011); Kumar (2013); Fontana e Macagnan (2013).

A relevância dos intangíveis é reconhecida pelos usuários independentemente do termo utilizado. Tais usuários defendem que a falha ou ineficiência de mercado é consequência da má evidenciação de informações sobre os intangíveis nas empresas (Lev \& Radhakrishnan, 2003, Moura, Varela \& Beuren, 2014). 
O destaque desses recursos tem forçado muitos gestores a utilizarem novas abordagens de planejamento. Essas abordagens auxiliam a medir o sucesso das operações dos negócios ao longo do tempo (Usoff, Thibodeau \& Burnaby, 2002).

\subsection{Abordagens de avaliação de ativos intangíveis}

Encontram-se na literatura diferentes abordagens de avaliação de ativos intangíveis e níveis de detalhamento, que variam de acordo com os objetivos de cada abordagem proposta. Apresenta-se, na Tabela 2, algumas das abordagens de avaliação de ativos intangíveis citadas na literatura.

Tabela 2

Abordagens de avaliação de ativos intangíveis

\begin{tabular}{|c|c|c|}
\hline $\begin{array}{l}\text { Abordagens de Avaliação } \\
\text { de Ativos Intangíveis }\end{array}$ & Autor & Contextualização \\
\hline Skandia Navigator & $\begin{array}{c}\text { Edvinsson e Malone } \\
\text { (1997) }\end{array}$ & $\begin{array}{l}\text { Foi projetado para fornecer uma imagem equilibrada da } \\
\text { situação financeira e do capital intelectual. Os ativos } \\
\text { intangíveis devem ser analisados sob várias perspectivas } \\
\text { para que se permita obter uma ideia do todo. }\end{array}$ \\
\hline Balanced Scorecard (BSC) & $\begin{array}{l}\text { Kaplan e Norton } \\
(1992,1993,1996)\end{array}$ & $\begin{array}{l}\text { É uma ferramenta que tem como objetivo criar uma visão } \\
\text { integrada de sistema de medição de gestão, incluindo } \\
\text { tanto elementos financeiros quanto não financeiros } \\
\text { (mercado, processos internos e aprendizado) que } \\
\text { influenciam no desempenho organizacional. }\end{array}$ \\
\hline Intangible Assets Monitor & Sveiby $(1998,1997)$ & $\begin{array}{l}\text { Tem o objetivo de orientar os gestores na utilização de } \\
\text { ativos intangíveis, na identificação e renovação desses } \\
\text { fluxos e estoques evitando a perda deles. Essa } \\
\text { ferramenta está focada em três tipos de ativos } \\
\text { intangíveis: ativos estrutura externa, ativos estrutura } \\
\text { interna e competência dos ativos empregados. }\end{array}$ \\
\hline Q de Tobin & $\begin{array}{l}\text { Stewart (1997) e } \\
\text { Bontis (1999) }\end{array}$ & $\begin{array}{l}\text { É uma das primeiras abordagens para medir o capital } \\
\text { intelectual das empresas. Essa ferramenta desenvolvida } \\
\text { pelo ganhador do Prêmio Nobel James Tobin mede a } \\
\text { relação entre o valor de mercado e o valor de reposição } \\
\text { dos ativos físicos organizacionais. }\end{array}$ \\
\hline Technology Broker & Brooking (1996) & $\begin{array}{l}\text { O autor defende que o capital intelectual pode ser obtido } \\
\text { com base no diagnóstico e análise das respostas a um } \\
\text { questionário de vinte perguntas. Esse questionário deve } \\
\text { cobrir os quatro componentes dos ativos intangiveis: } \\
\text { mercado, recursos humanos, capacidade intelectual e } \\
\text { infraestrutura. }\end{array}$ \\
\hline $\begin{array}{l}\text { A Diferença entre o Valor de } \\
\text { Mercado e o Valor Contábil }\end{array}$ & $\begin{array}{l}\text { Stewart }(1997) \text { e } \\
\text { Luthy (1998) }\end{array}$ & $\begin{array}{l}\text { Sua ideia central consiste na afirmativa de que o valor } \\
\text { dos ativos intangíveis de uma empresa é igual à } \\
\text { diferença entre seu valor de mercado e o registrado nas } \\
\text { demonstrações contábeis. }\end{array}$ \\
\hline $\begin{array}{l}\text { Fórmula do Capital } \\
\text { Intelectual da Skandia }\end{array}$ & $\begin{array}{c}\text { Edvinsson e Malone } \\
\text { (1998) }\end{array}$ & $\begin{array}{l}\text { O valor do Capital Intelectual é o produto entre o valor } \\
\text { monetário investido nos elementos do Capital Intelectual } \\
\text { e o coeficiente de eficiência relativo ao investimento } \\
\text { realizado. }\end{array}$ \\
\hline Intangibles-Driven-Earnings & Lev (2004) & $\begin{array}{l}\text { Em linhas gerais, capta a percepção do mercado sobre } \\
\text { os elementos intangíveis da organização ao comparar } \\
\text { seu valor de mercado com o valor projetado de Capital } \\
\text { intelectual, gerado a partir do Resultado Operacional } \\
\text { Bruto e da Rentabilidade do Ativo. }\end{array}$ \\
\hline
\end{tabular}

Nota. Fonte: adaptado de Pablos, P. O. de. (2003). Intellectual capital reporting in Spain: a comparative view. Journal of Intellectual Capital, 4(1); Antunes, M. T. P., \& Martins, E. (2007). Capital intelectual: seu entendimento e seus impactos no desempenho de grandes empresas brasileiras. BASE - Revista de Administração e Contabilidade da UNISINOS, 4(1); Schnorrenberger, D. (2005). Identificando e avaliando os ativos intangíveis de uma organização visando seu gerenciamento: uma ilustração na área econômico-financeira. Tese de doutorado, Universidade Federal de Santa Catarina, Florianópolis, SC, Brasil. 
Observa-se, com a apresentação das abordagens, que foram desenvolvidas dentro da mesma década, com exceção da Intangibles-Drives-Earnings, desenvolvida em 2004. As demais, todas foram criadas na década de 1990.

\subsection{Categorias das abordagens de avalição de ativos intangíveis}

Sveiby (2001) propôs agrupar as abordagens em quatro categorias, de acordo com o enfoque e o nível de desdobramento: (i) Avaliação Direta - Direct Intellectual Capital Methods (DIC); (ii) Avaliação pelo valor de Mercado - Market Capitalization Methods (MCM); (iii) Avaliação do Retorno dos Ativos - Return on Assets Methods (ROA); e (iv) Avaliação por Placares Equilibrados - Scorecards Methods (SC), conforme demonstração na Tabela 3.

Tabela 3

Categorias das abordagens de avaliação de ativos intangíveis

\begin{tabular}{|c|c|}
\hline $\begin{array}{l}\text { Categorias das abordagens } \\
\text { de avaliação de ativos } \\
\text { intangíveis }\end{array}$ & Conceito \\
\hline Avaliação Direta & $\begin{array}{l}\text { Calcula o valor monetário dos ativos intangíveis pela identificação dos seus } \\
\text { vários componentes que, quando estimados, podem ser diretamente avaliados } \\
\text { como um coeficiente agregado. }\end{array}$ \\
\hline $\begin{array}{c}\text { Avaliação pelo valor de } \\
\text { Mercado }\end{array}$ & $\begin{array}{l}\text { Calcula a diferença entre a capitalização de mercado de uma companhia e os } \\
\text { ativos dos acionistas, como o valor de seus recursos importantes ou ativos } \\
\text { intangíveis. }\end{array}$ \\
\hline $\begin{array}{l}\text { Avaliação do Retorno dos } \\
\text { Ativos }\end{array}$ & $\begin{array}{l}\text { A média das receitas antes dos impostos de uma empresa em um determinado } \\
\text { período é dividida pela média de valor dos seus ativos tangíveis. O resultado é } \\
\text { o ROA, que é então comparado com a média do seu segmento. A diferença é } \\
\text { multiplicada pela média dos seus ativos tangíveis para calcular a média anual } \\
\text { de receitas dos intangíveis. Dividindo a média superior pelo custo médio de } \\
\text { capital ou uma taxa de juros, pode-se obter uma estimativa do valor dos Ativos } \\
\text { Intangíveis ou Capital Intelectual. }\end{array}$ \\
\hline $\begin{array}{l}\text { Avaliação por Placares } \\
\text { Equilibrados }\end{array}$ & $\begin{array}{l}\text { Os vários componentes de ativos intangíveis ou do capital intelectual são } \\
\text { identificados e os indicadores e os deslocamentos predeterminados são } \\
\text { gerados e relatados nos scorecards ou como gráficos. }\end{array}$ \\
\hline
\end{tabular}

Nota. Fonte: Adaptado de Sveiby, K. E. (2001). Methods for Measuring Intangible Assets. Recuperado em 01 de julho, 2016, de http://www.sveiby.com/articles/IntangibleMethods.htm.

Ao longo de seu trabalho, Schnorrenberger (2005) desenvolveu uma análise sucinta das abordagens de avaliação de ativos intangíveis encontradas com maior frequência na literatura ao todo foram analisadas 21 . Assim, como cada uma tem suas peculiaridades, foram divididas de acordo com o enfoque e as quatro categorias apresentadas anteriormente. Dentro de cada categoria foram listadas as respectivas abordagens, conforme Figura 1. 


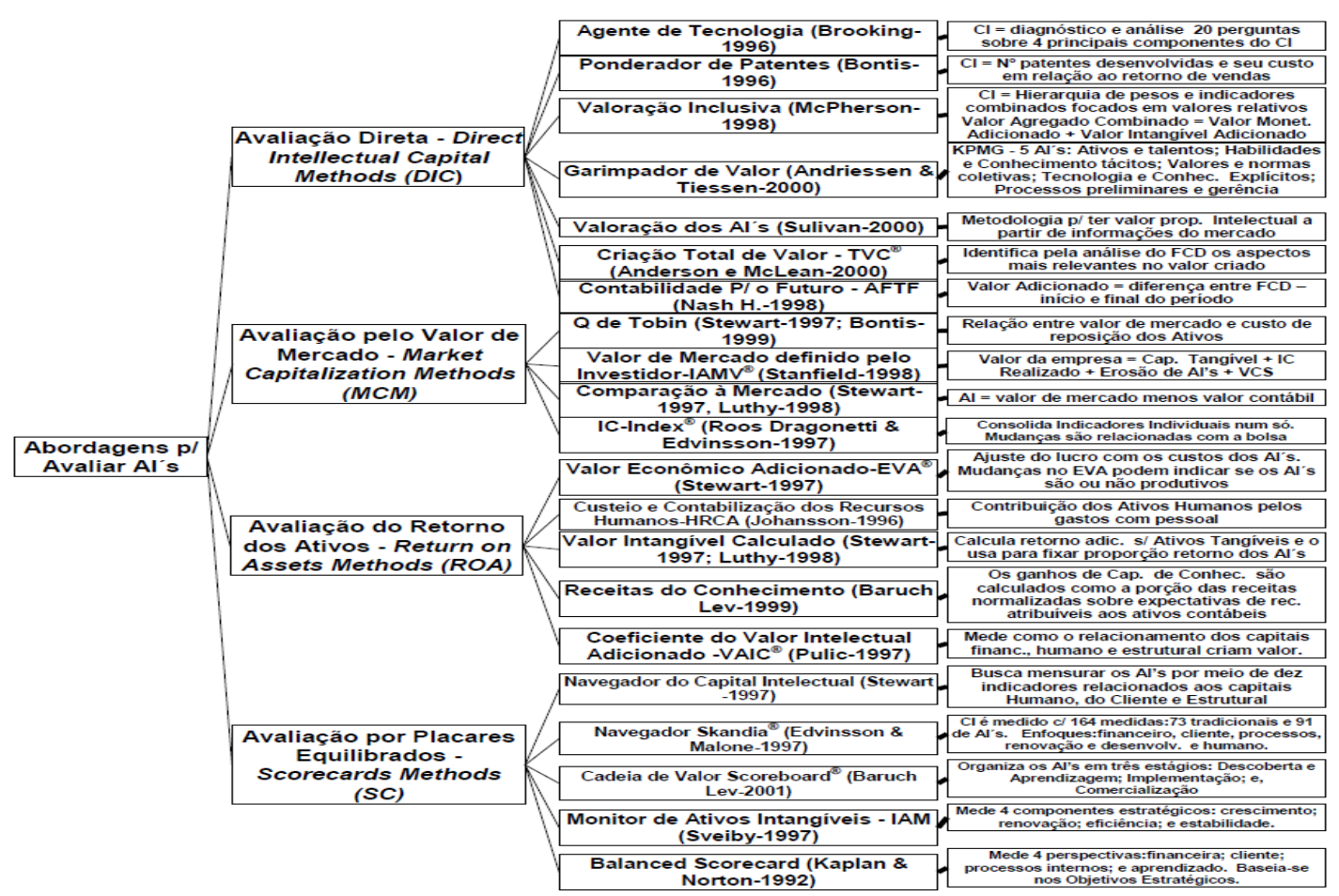

Figura 1. Categorias e respectivas abordagens de avaliação de ativos intangíveis Fonte: Schnorrenberger, D. (2005). Identificando e avaliando os ativos intangíveis de uma organização visando seu gerenciamento: uma ilustração na área econômico-financeira. Tese de doutorado, Universidade Federal de Santa Catarina, Florianópolis, SC, Brasil.

A partir da Figura 1 e com o desenvolvimento do presente estudo, foi possível classificar as abordagens de avaliação de intangíveis mais citadas na literatura quanto às suas categorias e enquadramento.

\subsection{Enquadramento das abordagens de avaliação de ativos intangíveis}

Schnorrenberger (2005) enquadrou as abordagens de avaliação, de acordo com o grau de personalização, detalhamento e integração dos resultados, em: (i) padrão; (ii) misto; (iii) personalizado; (iv) mensura globalmente; (vi) identifica e mensura localmente e (vii) identifica, avalia - local e globalmente - e gerencia, conforme apresentação na Tabela 4.

Tabela 4

Enquadramento das abordagens de avaliação de ativos intangíveis

\begin{tabular}{c|l}
\hline Enquadramento & \multicolumn{1}{c}{ Conceito } \\
\hline Padrão & $\begin{array}{l}\text { São aquelas abordagens que apresentam uma estrutura julgada válida } \\
\text { para todas as situações e empresas. }\end{array}$ \\
\hline Misto & $\begin{array}{l}\text { São as abordagens que buscam estabelecer alguns padrões e também } \\
\text { reconhecem que devem existir adaptações para cada situação. }\end{array}$ \\
\hline Mensura globalmente & $\begin{array}{l}\text { São as abordagens que partem do pressuposto que, em se tratando de } \\
\text { ativos intangíveis, cada situação é única. }\end{array}$ \\
\hline Identifica e Mensura Localmente & $\begin{array}{l}\text { São as abordagens que buscam identificar um valor global para os ativos } \\
\text { intangíveis, sem identificar os itens que o compõem. }\end{array}$ \\
\hline $\begin{array}{c}\text { São as abordagens que buscam conhecer quais os ativos intangíveis de } \\
\text { uma organização, além de conhecer seu desempenho localmente. }\end{array}$ \\
Identifica, Avalia - Local e & $\begin{array}{l}\text { São as abordagens que buscam cobrir todo o processo, indo desde a } \\
\text { identificação dos ativos intangíveis, passando pela avaliação local e global, } \\
\text { fechando o ciclo com o seu gerenciamento. }\end{array}$ \\
\hline
\end{tabular}

Nota. Fonte: Schnorrenberger, D. (2005). Identificando e avaliando os ativos intangíveis de uma organização visando seu gerenciamento: uma ilustração na área econômico-financeira. Tese de doutorado, Universidade Federal de Santa Catarina, Florianópolis, SC, Brasil. 
Observa-se, portanto, no Quadro 4, que as abordagens de avaliação dos ativos intangíveis podem ser enquadradas em 6 categorias, iniciando com a categoria Padrão, que representa uma estrutura válida para todas as empresas e em todas as situações, e terminando com a categoria Identifica, avalia, Local e Globalmente, e gerencia, que representa uma abordagem completa, identifica os ativos intangíveis, avalia globalmente e gerencia-os.

\section{PROCEDIMENTOS METODOLÓGICOS}

Nesta seção são abordados os aspectos relativos ao enquadramento metodológico da pesquisa, assim como o instrumento de intervenção empregado no estudo.

\subsection{Enquadramento metodológico}

Quanto ao enquadramento metodológico, no que se refere aos objetivos, o estudo caracteriza-se como exploratório-descritivo, pois, se propôs a selecionar um PB para familiarização com o tema ativo intangível, e classifica-se como descritivo por descrever as características encontradas no PB de destaque dentro da área de interesse (Markoni \& Lakatos, 2003).

Quanto à abordagem do problema, o estudo caracteriza-se como qualitativo. Para análise qualitativa dos dados empregou-se as três etapas expostas por Miles e Huberman (1994 como citado em Gil 2008): redução, exibição e conclusão/verificação. A etapa de redução é o processo de seleção do PB para futura simplificação dos dados. A etapa de exibição consiste em organizar, apresentar e analisar os dados. Por fim, na etapa de conclusão/verificação se faz uma revisão dos dados para então verificar o enquadramento das publicações sobre o tema intangível.

Para levantamento dos dados utilizou-se o procedimento de pesquisa bibliográfica, informado pelo Proknow- $C$, pois, para desenvolvimento do artigo, buscou-se, nas bases de dados disponibilizadas pela CAPES, trabalhos já realizados e revestidos de importância, sobre ativos intangíveis (Markoni \& Lakatos, 2003).

\subsection{Instrumento de intervenção}

Utilizou-se para realização deste trabalho o ProKnow- $C$, que é composto de quatro etapas: (i) seleção de um portfólio de artigos sobre o tema da pesquisa; (ii) análise bibliométrica do portfólio; (iii) análise sistêmica e (iv) definição da pergunta e objetivo da pesquisa (Ensslin, Ensslin, Kremer, Chaves \& Borgert, 2014). Contudo, nesta pesquisa, foram cumpridas as duas primeiras fases, que contemplam a revisão da literatura necessária.

\subsubsection{Procedimentos para coleta dos dados}

Para alcance do objetivo desta pesquisa, fez-se a seleção do portfólio bibliográfico, etapa que permite que os pesquisadores reúnam um banco de artigos relacionados com o tema, alinhado de acordo com a percepção e delimitações de cada pesquisador. Nesta etapa, executa-se três fases: (i) a seleção dos artigos nas bases de dados que compõem o banco de artigos bruto; (ii) a filtragem dos artigos selecionados com base no alinhamento da pesquisa e (iii) o teste de representatividade do portfólio bibliográfico. No final da etapa constitui-se o portfólio bibliográfico (PB), que corresponde a um conjunto de artigos considerado relevante sobre o tema (Ensslin et al., 2014).

\subsubsection{Seleção do banco de artigos bruto}

Para iniciar o processo são definidos os eixos de pesquisa. Portanto, para conhecer as pesquisas científicas, que representam o fragmento da literatura relativo ao tema ativos intangíveis, definiu-se o seguinte eixo de pesquisa: Intangível.

Após a definição do eixo, parte-se para a etapa de formação do banco de artigos bruto, composta de quatro fases: (i) definição das palavras-chave; (ii) definição da base de dados; (iii) busca pelos artigos nas bases de dados com as palavras-chave e (iv) realização de teste de aderência das palavras-chave (Ensslin et al., 2014). 
(i) Definição de palavras-chave

Definiu-se as seguintes palavras-chave para o eixo: ("Capital Intelectual" ou "Ativo Intangível*") e ("Organização*"). O uso do asterisco após as palavras fez-se necessário para que as pesquisas alcançassem as variações verbais ou substantivas das palavras.

\section{(ii) Definição das bases de dados}

Após a deliberação dos eixos e a definição das palavras-chave, passa-se a definir as bases de dados para efetuar a busca dos artigos. Definiu-se as seguintes bases alinhadas com a área de conhecimento ciências sociais aplicadas disponibilizadas na CAPES: EBSCO; ProQuest; Scopus e Science Direct para busca dos artigos internacionais de língua inglesa e a base Spell para revisão nacional.

Com a definição das palavras-chave e das bases de dados inicia-se o processo de busca de tais palavras. Na presente pesquisa definiu-se que a representatividade das bases de dados seria de $100 \%$, ou seja, bastando retornar pelo menos 1 artigo para se manter no processo. Para a busca, aplicou-se o comando, observando a estrutura e os parâmetros específicos em cada base de dados. Como delimitações do processo de busca destacam-se: (i) artigos publicados em periódicos científicos e (ii) pesquisa com as palavras-chave no título, resumo ou palavras-chave.

(iii) Busca pelos artigos nas bases de dados com as palavras-chave

$\mathrm{Na}$ busca, feita conforme as delimitações citadas anteriormente, encontrou-se 1.367 artigos internacionais e 305 artigos nacionais que compõem o banco de artigos bruto. Essas publicações foram exportadas para o software $E n d N o t e \AA ~ X 7$ para que se pudesse prosseguir com a análise.

(iv) Realização de teste de aderência das palavras-chave

Nesta etapa, selecionou-se os artigos considerados alinhados ao tema, para verificar a necessidade de inclusão de novas palavras-chave. Dessa forma, selecionou-se 5 artigos do banco de artigos bruto e verificou-se as palavras-chave com aquelas utilizadas para busca. Verificou-se, portanto, que não haveria necessidade de incluir novas palavras-chave, pois já estavam alinhadas ao tema.

\subsubsection{Filtragem do banco de artigos bruto}

Após selecionar o banco de artigos bruto, o processo de seleção do PB continua com a filtragem, a qual é feita com as seguintes considerações: (i) exclusão de artigos repetidos/ redundantes; (ii) alinhamento dos artigos ao tema quanto ao título; (iii) reconhecimento científico dos artigos; (iv) alinhamento dos artigos ao tema quanto aos resumos e (v) disponibilidade dos artigos na íntegra.

A primeira fase, exclusão de artigos repetidos/redundantes, foi realizada com o uso do sofware EndNote ${ }^{\circledR}$ X7. Excluíram-se 977 publicações internacionais e 195 nacionais que estavam duplicadas no banco bruto de artigos, restando um total de 390 artigos internacionais e 110 nacionais para análise de alinhamento dos artigos quanto ao título. Nessa etapa, foram lidos os títulos dos 500 artigos e eliminados 40 artigos internacionais e 20 nacionais. Sendo assim, restaram 350 artigos internacionais e 90 nacionais não repetidos e com o título alinhado.

Em seguida, verificou-se o número de citações que cada um dos 440 artigos possuía, por meio do google acadêmico. Assim, selecionou-se para leitura dos resumos todos os artigos que possuíam 10 citações ou mais, o que representou o total de 188 artigos.

$\mathrm{Na}$ quarta fase, alinhamento dos artigos ao tema quanto aos resumos, foram lidos os resumos dos 188 artigos que compõem o banco de artigos não repetidos com títulos alinhados e reconhecimento científico. Nessa fase, eliminou-se 112 artigos. Assim, no banco de artigos não repetidos com título e resumo alinhados permaneceram 76 artigos.

Verificou-se, ainda, dentre os 76 artigos, aqueles que estavam disponíveis gratuitamente na íntegra, o que resultou em 57 artigos, e na eliminação de 19 artigos que não estavam disponíveis. A fim de verificar o alinhamento dos artigos na íntegra, foram lidos por 
completo os 57 artigos que estavam disponíveis, dentre os quais foram selecionados 15 artigos internacionais e 13 nacionais, que compõem o banco de artigos do PB. A Tabela 5 apresenta os artigos que compõem o PB.

\section{Tabela 5}

\section{Artigos selecionados para compor o PB}

\begin{tabular}{|c|c|c|c|c|c|}
\hline Artigos & Título & Ano & Citações & Autores & Revista \\
\hline \multirow{15}{*}{ 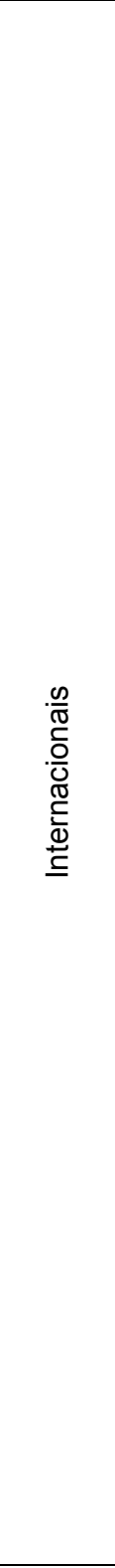 } & $\begin{array}{l}\text { Measuring your company's } \\
\text { intellectual performance }\end{array}$ & 1997 & 1103 & Roos, G.; Roos, J. & Long Range Planning \\
\hline & The Intangible Assets Monitor & 1997 & 607 & Sveiby, Karl Erik & $\begin{array}{c}\text { Journal of Human } \\
\text { Resource Costing \& } \\
\text { Accounting } \\
\end{array}$ \\
\hline & $\begin{array}{l}\text { The importance of intellectual } \\
\text { capital and its effect on } \\
\text { performance measurement } \\
\text { systems }\end{array}$ & 2002 & 74 & $\begin{array}{l}\text { Usoff, Catherine A.; } \\
\text { Thibodeau, Jay C.; } \\
\text { Burnaby, Priscilla }\end{array}$ & $\begin{array}{l}\text { Managerial Auditing } \\
\text { Journal }\end{array}$ \\
\hline & $\begin{array}{l}\text { Intellectual capital reporting in } \\
\text { Spain: a comparative view }\end{array}$ & 2003 & 228 & $\begin{array}{c}\text { Pablos, Patricia Ordonez } \\
\text { de }\end{array}$ & $\begin{array}{c}\text { Journal of Intellectual } \\
\text { Capital }\end{array}$ \\
\hline & $\begin{array}{l}\text { Intellectual capital: Measurement } \\
\text { effectiveness }\end{array}$ & 2004 & 191 & $\begin{array}{l}\text { Kannan, Gopika; Aulbur, } \\
\text { Wilfried G. }\end{array}$ & $\begin{array}{c}\text { Journal of Intellectual } \\
\text { Capital }\end{array}$ \\
\hline & $\begin{array}{l}\text { The dominance of intangible } \\
\text { assets: consequences for } \\
\text { enterprise management and } \\
\text { corporate reporting }\end{array}$ & 2004 & 134 & $\begin{array}{l}\text { Lev, Baruch; Daum, } \\
\text { Juergen } \mathrm{H} \text {. }\end{array}$ & $\begin{array}{l}\text { Measuring Business } \\
\text { Excellence }\end{array}$ \\
\hline & $\begin{array}{l}\text { Managing and reporting } \\
\text { knowledge-based resources and } \\
\text { processes in research } \\
\text { organisations: specifics, lessons } \\
\text { learned and perspectives }\end{array}$ & 2004 & 122 & $\begin{array}{l}\text { Leitner, Karl-Heinz; } \\
\text { Warden, Campbell }\end{array}$ & $\begin{array}{c}\text { Management } \\
\text { Accounting Research }\end{array}$ \\
\hline & $\begin{array}{l}\text { Comparative justification on } \\
\text { intellectual capital }\end{array}$ & 2004 & 98 & $\begin{array}{c}\text { Seetharaman, A.; Low, } \\
\text { Kevin Teng; Saravanan, } \\
\text { A. S. }\end{array}$ & $\begin{array}{l}\text { Journal of Intellectual } \\
\text { Capital }\end{array}$ \\
\hline & $\begin{array}{l}\text { Managing and reporting intangible } \\
\text { assets in research technology } \\
\text { organisations }\end{array}$ & 2005 & 87 & Leitner, K. H. & $\mathrm{R}$ and $\mathrm{D}$ Management \\
\hline & $\begin{array}{l}\text { An integrated framework for } \\
\text { visualising intellectual capital }\end{array}$ & 2005 & 76 & $\begin{array}{l}\text { Boedker, C.; Guthrie, J.; } \\
\text { Cuganesan, S. }\end{array}$ & $\begin{array}{c}\text { Journal of Intellectual } \\
\text { Capital }\end{array}$ \\
\hline & $\begin{array}{l}\text { The IC Rating }{ }^{\mathrm{TM}} \text { model by } \\
\text { Intellectual Capital Sweden }\end{array}$ & 2005 & 70 & $\begin{array}{l}\text { Jacobsen, K.; Hofman- } \\
\text { Bang, P.; Nordby Jr, R. }\end{array}$ & $\begin{array}{c}\text { Journal of Intellectual } \\
\text { Capital }\end{array}$ \\
\hline & $\begin{array}{l}\text { The German guideline for } \\
\text { intellectual capital reporting: } \\
\text { method and experiences }\end{array}$ & 2007 & 34 & $\begin{array}{l}\text { Manfred, Bornemann; } \\
\text { Kay, Alwert }\end{array}$ & $\begin{array}{c}\text { Journal of Intellectual } \\
\text { Capital }\end{array}$ \\
\hline & $\begin{array}{l}\text { A framework for prioritization of } \\
\text { intellectual capital indicators in } \\
\text { R\&D }\end{array}$ & 2009 & 49 & $\begin{array}{l}\text { Kim, Dong-Young; } \\
\text { Kumar, Vinod }\end{array}$ & $\begin{array}{c}\text { Journal of Intellectual } \\
\text { Capital }\end{array}$ \\
\hline & $\begin{array}{l}\text { Analysis and Valuation of } \\
\text { Intellectual Capital According to Its } \\
\text { Context }\end{array}$ & 2009 & 18 & Ortiz, Miguel Angel Axtle & $\begin{array}{l}\text { Journal of Intellectual } \\
\text { Capital }\end{array}$ \\
\hline & \begin{tabular}{|l|} 
Intellectual capital models in \\
Spanish public sector \\
\end{tabular} & 2010 & 56 & Ramirez, Yolanda & $\begin{array}{c}\text { Journal of Intellectual } \\
\text { Capital }\end{array}$ \\
\hline \multirow{4}{*}{$\begin{array}{l}\frac{0}{\pi} \\
\frac{0}{0} \\
\frac{O}{0} \\
\frac{\pi}{Z}\end{array}$} & Medindo o capital intelectual & 2001 & 76 & Joia & $\begin{array}{c}\text { Revista de } \\
\text { Administração de } \\
\text { Empresas }\end{array}$ \\
\hline & $\begin{array}{l}\text { A gestão do conhecimento: } \\
\text { conectando estratégia e valor para } \\
\text { a empresa }\end{array}$ & 2002 & 36 & Francini & RAE-eletrônica \\
\hline & $\begin{array}{l}\text { Um estudo exploratório do controle } \\
\text { gerencial de ativos e recursos } \\
\text { intangíveis em empresas } \\
\text { brasileiras }\end{array}$ & 2002 & 40 & Barbosa; Gomes & $\begin{array}{c}\text { Revista de } \\
\text { Administração } \\
\text { Contemporânea }\end{array}$ \\
\hline & $\begin{array}{l}\text { Capital intelectual: verdades e } \\
\text { mitos }\end{array}$ & 2002 & 95 & Antunes; Martins & $\begin{array}{l}\text { Revista Contabilidade } \\
\text { \& Finanças - USP }\end{array}$ \\
\hline
\end{tabular}


Tabela 5 (continuação)

\begin{tabular}{|c|c|c|c|c|c|}
\hline Artigos & Título & Ano & Citações & Autores & Revista \\
\hline \multirow{8}{*}{$\begin{array}{l}\frac{\infty}{\pi} \\
\frac{0}{0} \\
\frac{0}{0} \\
\frac{\pi}{Z}\end{array}$} & $\begin{array}{l}\text { O tratamento contábil do capital } \\
\text { intelectual em empresas com valor } \\
\text { de mercado superior ao valor } \\
\text { contábil }\end{array}$ & 2003 & 34 & Oliveira; Beuren & $\begin{array}{l}\text { Revista Contabilidade } \\
\text { \& Finanças - USP }\end{array}$ \\
\hline & $\begin{array}{l}\text { A Controladoria e o Capital } \\
\text { Intelectual: um estudo empírico } \\
\text { sobre sua gestão }\end{array}$ & 2006 & 49 & Antunes & $\begin{array}{l}\text { Revista Contabilidade } \\
\text { \& Finanças - USP }\end{array}$ \\
\hline & $\begin{array}{l}\text { Ativos intangíveis e o desempenho } \\
\text { empresarial }\end{array}$ & 2006 & 135 & Perez; Famá & $\begin{array}{l}\text { Revista Contabilidade } \\
\text { \& Finanças - USP }\end{array}$ \\
\hline & $\begin{array}{l}\text { Gerenciando o Capital Intelectual: } \\
\text { uma proposta baseada na } \\
\text { controladoria de grandes } \\
\text { empresas brasileiras }\end{array}$ & 2007 & 17 & Antunes, Martins & $\begin{array}{l}\text { REAd. Revista } \\
\text { Eletrônica de } \\
\text { Administração }\end{array}$ \\
\hline & $\begin{array}{l}\text { Capital intelectual: seu } \\
\text { entendimento e seus impactos no } \\
\text { desempenho de grandes } \\
\text { empresas brasileiras }\end{array}$ & 2007 & 26 & Antunes, Martins & $\begin{array}{l}\text { BASE - Revista de } \\
\text { Administração e } \\
\text { Contabilidade da } \\
\text { UNISINOS } \\
\end{array}$ \\
\hline & $\begin{array}{l}\text { Um estudo reflexivo da produção } \\
\text { científica em capital intelectual }\end{array}$ & 2008 & 14 & $\begin{array}{l}\text { Gallon; Souza; Rover; } \\
\text { Ensslin }\end{array}$ & $\begin{array}{l}\text { Revista de } \\
\text { Administração } \\
\text { Mackenzie }\end{array}$ \\
\hline & $\begin{array}{l}\text { Marcas, patentes e criação de } \\
\text { valor }\end{array}$ & 2008 & 27 & Teh; Kayo; Kimura & $\begin{array}{c}\text { Revista de } \\
\text { Administração } \\
\text { Mackenzie } \\
\end{array}$ \\
\hline & $\begin{array}{l}\text { Determinantes da formação do } \\
\text { Capital Intelectual nas empresas } \\
\text { produtoras de Tecnologia da } \\
\text { Informação e Comunicação }\end{array}$ & 2011 & 10 & Lima; Carmona & $\begin{array}{l}\text { Revista de } \\
\text { Administração } \\
\text { Mackenzie }\end{array}$ \\
\hline
\end{tabular}

Nota. Fonte: dados da pesquisa.

Dessa forma, os 28 artigos compuseram o PB e foram utilizados nesta pesquisa para investigar as abordagens de avaliação de intangíveis, levantando as categorias e o enquadramento das abordagens mais frequentes.

\subsubsection{Procedimentos para análise dos dados}

Após a seleção do PB, iniciou-se a análise dos artigos. Levantou-se inicialmente as abordagens de avaliação dos ativos intangíveis citadas pelos artigos do PB. Em seguida, verificou-se suas categorias e enquadramento, conforme protocolo de busca apresentado na Figura 2. 


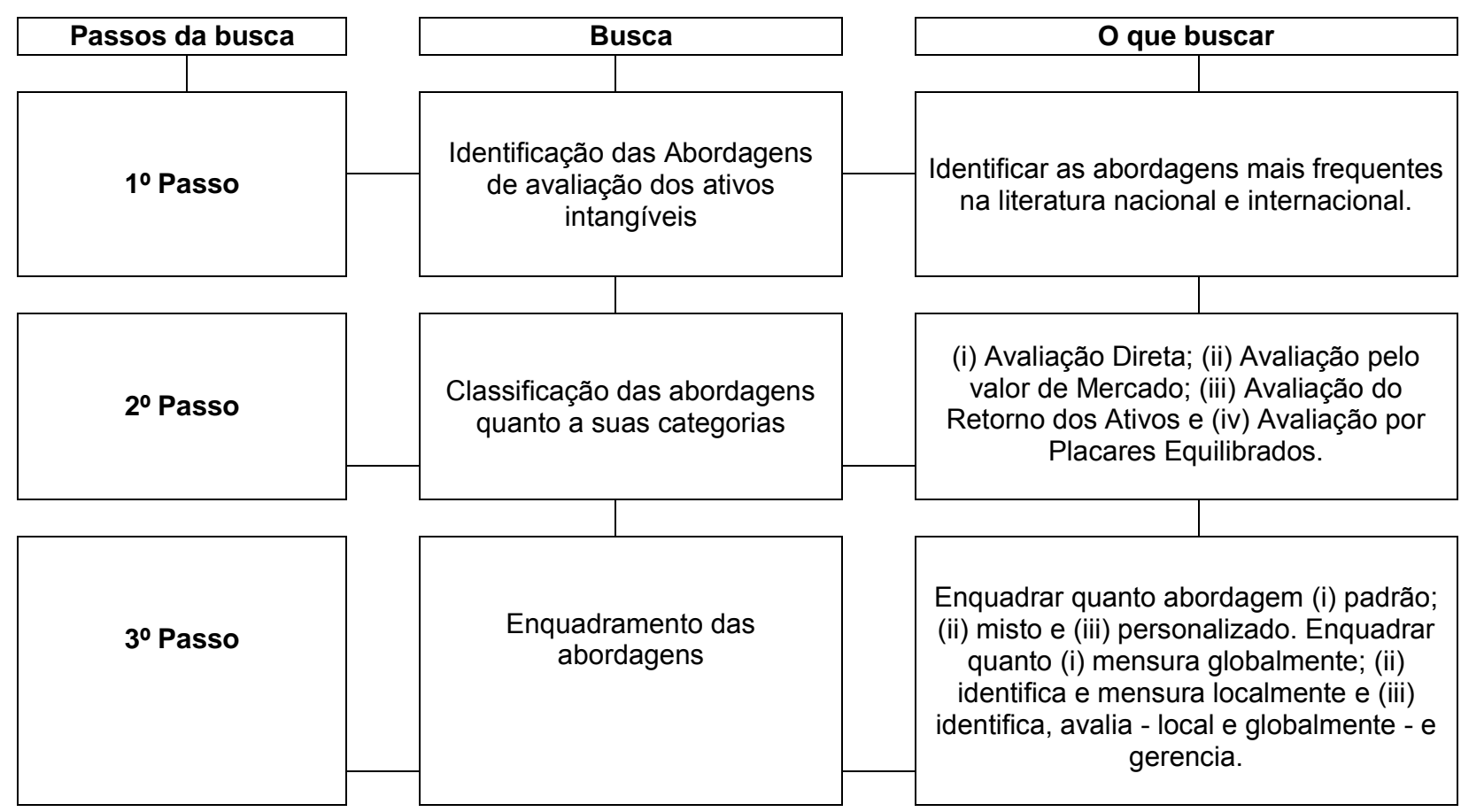

Figura 2. Protocolo de busca no PB

Fonte: dados da pesquisa.

Posteriormente à busca realizada por meio do protocolo criado, iniciou-se a análise dos dados coletados em julho de 2015.

\section{ANÁLISE DOS RESULTADOS}

Após a seleção do PB, iniciou-se a análise dos dados. Essa análise foi dividida em três etapas: (i) identificação das abordagens de avalição dos ativos intangíveis; (ii) assimilação das categorias das abordagens e (iii) enquadramento das abordagens de avaliação de ativos intangíveis.

\subsection{Abordagens de avaliação de ativos intangíveis}

Quanto às abordagens de avaliação de ativos intangíveis, identificou-se o total de 28 citadas pelos artigos internacionais e 18 citadas nos artigos nacionais. Após a identificação individual das publicações nacionais e internacionais, fez-se a junção das abordagens e observou-se o total de 41 abordagens de avaliação dos ativos intangíveis, apresentadas na Tabela 6.

Tabela 6

Abordagens de avaliação de ativos intangíveis citados no PB

\begin{tabular}{l|l|c|c|c}
\hline $\mathbf{N r}$ & Abordagens de Avaliação de Ativos Intangíveis & $\begin{array}{c}\text { Frequência } \\
\text { Internacional }\end{array}$ & $\begin{array}{c}\text { Frequência } \\
\text { Nacional }\end{array}$ & $\begin{array}{c}\text { Frequência } \\
\text { Total }\end{array}$ \\
\hline 1 & Skandia Navigator & 5 & 6 & 11 \\
\hline 2 & Balanced Scorecard (BSC) & 5 & 3 & 8 \\
\hline 3 & Intangible Assets Monitor & 5 & 3 & 8 \\
\hline 4 & Q de Tobin & 4 & 2 & 6 \\
\hline 5 & Technology Broker & 2 & 3 & 5 \\
\hline 6 & A Diferença entre o Valor de Mercado e o Valor Contábil & 0 & 5 & 5 \\
\hline 7 & Fórmula do Capital Intelectual da Skandia & 0 & 3 & 3 \\
\hline 8 & Intangibles-Driven-Earnings & 0 & 3 & 3 \\
\hline
\end{tabular}


Tabela 6 (continuação)

\begin{tabular}{|c|c|c|c|c|}
\hline $\mathbf{N r}$ & Abordagens de Avaliação de Ativos Intangíveis & $\begin{array}{l}\text { Frequência } \\
\text { Internacional }\end{array}$ & $\begin{array}{l}\text { Frequência } \\
\text { Nacional }\end{array}$ & $\begin{array}{l}\text { Frequência } \\
\text { Total }\end{array}$ \\
\hline 9 & Competence Strategic Management Model & 1 & 0 & 1 \\
\hline 10 & Knowledge production function & 1 & 0 & 1 \\
\hline 11 & Knowledge capital scorecard & 1 & 0 & 1 \\
\hline 12 & The intellectual capital accounts & 1 & 0 & 1 \\
\hline 13 & Market to book ratio $(\mathrm{p} / \mathrm{b})$ & 1 & 0 & 1 \\
\hline 14 & Calculate intangible value (CIV) & 1 & 0 & 1 \\
\hline 15 & Knowledge capital earnings (KCE) & 1 & 0 & 1 \\
\hline 16 & Pricewaterhouse Coopers LLP overall value & 1 & 0 & 1 \\
\hline 17 & IC Rating & 1 & 0 & 1 \\
\hline 18 & Intellectual Capital Value Creation (ICVC) & 1 & 0 & 1 \\
\hline 19 & $\begin{array}{l}\text { Contextual intellectual capital components valuation } \\
\text { (CONICCVALTM) }\end{array}$ & 1 & 0 & 1 \\
\hline 20 & Framework for prioritizing intellectual capital (IC) & 1 & 0 & 1 \\
\hline 21 & The SICAP Project & 1 & 0 & 1 \\
\hline 22 & $\begin{array}{l}\text { The intellectual capital model proposed by Caba and } \\
\text { Sierra }\end{array}$ & 1 & 0 & 1 \\
\hline 23 & The intellectual capital model proposed by Garcı'a & 1 & 0 & 1 \\
\hline 24 & The intellectual capital model proposed by Bossi & 1 & 0 & 1 \\
\hline 25 & The model for Gamma Company & 1 & 0 & 1 \\
\hline 26 & The model for Epsilon Company & 1 & 0 & 1 \\
\hline 27 & The intellectual capital report & 1 & 0 & 1 \\
\hline 28 & Framework addresses IC valuation & 1 & 0 & 1 \\
\hline 29 & $\begin{array}{l}\text { A basic model for IC management and reporting for } \\
\text { research organisations }\end{array}$ & 1 & 0 & 1 \\
\hline 30 & $\begin{array}{l}\text { A model for measuring and valuing intangible assets in } \\
\text { RTOs }\end{array}$ & 1 & 0 & 1 \\
\hline 31 & Intellectual capital reporting framework & 1 & 0 & 1 \\
\hline 32 & $\begin{array}{l}\text { Modelo para avaliação do Capital Intelectual vinculando a } \\
\text { Estratégia Empresarial ao } \mathrm{Cl}\end{array}$ & 0 & 1 & 1 \\
\hline 33 & Cl-Index & 0 & 1 & 1 \\
\hline 34 & $\begin{array}{l}\text { Modelo conceitual de mensuração dos retornos dos } \\
\text { investimentos em capital intelectual }(\mathrm{Cl})\end{array}$ & 0 & 1 & 1 \\
\hline 35 & Framework of Intangible Valuation Areas (FIVA) & 0 & 1 & 1 \\
\hline 36 & Modelo Heurístico & 0 & 1 & 1 \\
\hline 37 & Declarações Holísticas & 0 & 1 & 1 \\
\hline 38 & Matriz de Ajuste, Custo e Valor & 0 & 1 & 1 \\
\hline 39 & Modelo de Barret & 0 & 1 & 1 \\
\hline 40 & Sistema Multidimensional & 0 & 1 & 1 \\
\hline \multirow[t]{2}{*}{41} & Value Explorer & 0 & 1 & 1 \\
\hline & Frequência Total & 44 & 38 & 82 \\
\hline
\end{tabular}

Nota. Fonte: dados da pesquisa.

Verifica-se, com a análise da Tabela 1, que Balanced Scorecard (Kaplan \& Norton, 1992, 1993, 1996), Skandia Navigator (Edvinsson \& Malone, 1997) e Intangible Assets Monitor (Sveiby, 1998, 1997) são as abordagens mais citadas pelos artigos do PB internacional, 
mencionadas em 5 dos 15 artigos. Em seguida apresenta-se o $Q$ de Tobin (Stewart 1997 e Bontis 1999), com 4 citações, e Technology Broker (Brooking, 1996), com 2 menções.

Já no cenário nacional identificou-se o total de 18 abordagens de avaliação dos ativos intangíveis. Skandia Navigator (Edvinsson \& Malone, 1997) foi a abordagem mais citada, com 6 citações, seguida da abordagem a diferença entre o valor de Mercado e o valor contábil (Stewart, 1997) mencionada 5 vezes. As abordagens Balanced Scorecard (Kaplan \& Norton, 1992,1993,1996), Intangible Assets Monitor (Sveiby, 1998, 1997), Technology Broker (Brooking, 1996), Fórmula do Capital Intelectual da Skandia (Edvinsson \& Malone, 1998), Intangibles-Driven-Earnings (Lev, 2004), aparecem sendo citadas por 3 artigos nacionais e a Q de Tobin (Stewart, 1997 e Bontis, 1999) é mencionada em 2 artigos.

Com as informações disponíveis, realizou-se o cruzamento das frequências das abordagens de avaliação nos artigos nacionais e nos artigos internacionais, conforme demonstração na Figura 3.
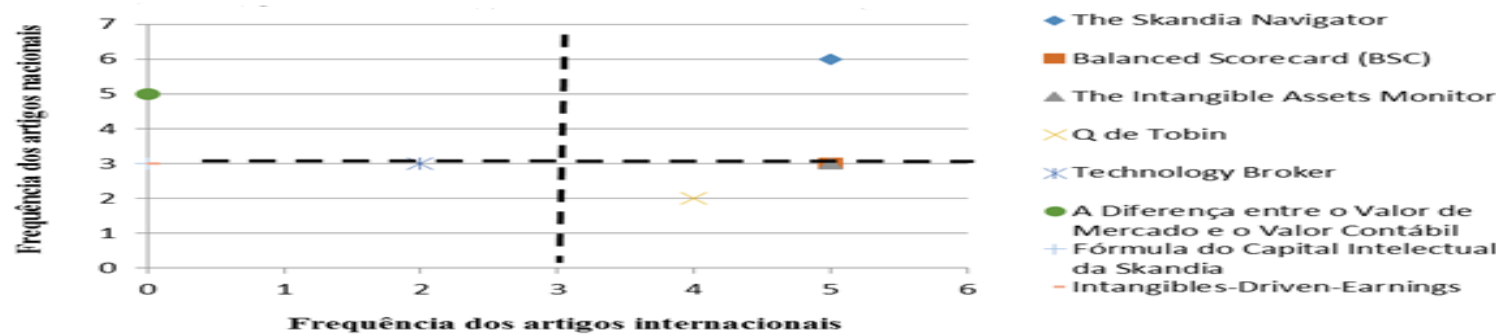

Figura 3. Cruzamento das abordagens de avaliação dos ativos intangíveis nas pesquisas nacionais e internacionais

Fonte: dados da pesquisa.

Desse modo, as abordagens de avaliação de ativos intangíveis mais citadas na literatura foram: (i) Skandia Navigator, (ii) Balanced Scorecard (BSC); (iii) Intangible Assets Monitor, (iv) $Q$ de Tobin; (v) Technology Broker, (vi) A Diferença entre o Valor de Mercado e o Valor Contábil; (vii) Fórmula do Capital Intelectual da Skandia e (viii) Intangibles-DrivenEarnings.

Observa-se que as abordagens mais citadas nos artigos internacionais e nacionais foram criadas nos anos de 1990, confirmando uma preocupação da época em desenvolver abordagens que avaliassem os ativos intangíveis, destacando a relevância desses ativos no meio organizacional.

\subsection{Categorias das abordagens de avaliação de ativos intangíveis}

A partir do levantamento das abordagens de avaliação de ativos intangíveis classificouse as abordagens, que foram citadas mais de uma vez nas pesquisas, conforme suas categorias. A classificação pode ser visualizada na Tabela 7.

Tabela 7

Categorias das abordagens de avaliação de intangíveis destacadas nas pesquisas nacionais e internacionais

\begin{tabular}{c|c}
\hline Abordagens de avaliação de intangíveis & Categorias \\
\hline The Skandia Navigator & Avaliação por placares equilibrados \\
\hline Balanced Scorecard (BSC) & Avaliação por placares equilibrados \\
\hline The Intangible Assets Monitor & Avaliação por placares equilibrados \\
\hline Q de Tobin & Avaliação pelo valor de mercado \\
\hline Technology Broker & Avaliação Direta \\
\hline A Diferença entre o Valor de Mercado e o Valor Contábil & Avaliação pelo valor de mercado \\
\hline Fórmula do Capital Intelectual da Skandia & Avaliação por placares equilibrados \\
\hline Intangibles-Driven-Earnings & Avaliação pelo valor de mercado
\end{tabular}

Nota. Fonte: dados da pesquisa.

Apresenta-se, portanto, que as abordagens que mais se destacaram classificam-se, em sua maioria, na categoria de avaliação por placares equilibrados, ou seja, buscam identificar os 
tipos de ativos intangíveis e gerar índices e indicadores com o propósito de representá-los em mapas e painéis.

Constatou-se, no entanto, que nenhuma abordagem se enquadrou na categoria de Avaliação do Retorno dos Ativos, que possui como vantagem competitiva a facilidade de obtenção e compreensão entre os técnicos do meio econômico-financeiro, por serem baseadas nas demonstrações contábeis tradicionais. Portanto, percebe-se que as abordagens mais citadas na literatura não se baseiam nas demonstrações contábeis.

\subsection{Enquadramento das abordagens de avaliação de ativos intangíveis}

Em seguida, buscou-se identificar o enquadramento das abordagens levantadas nos estudos, conforme apresentação na Figura 4.

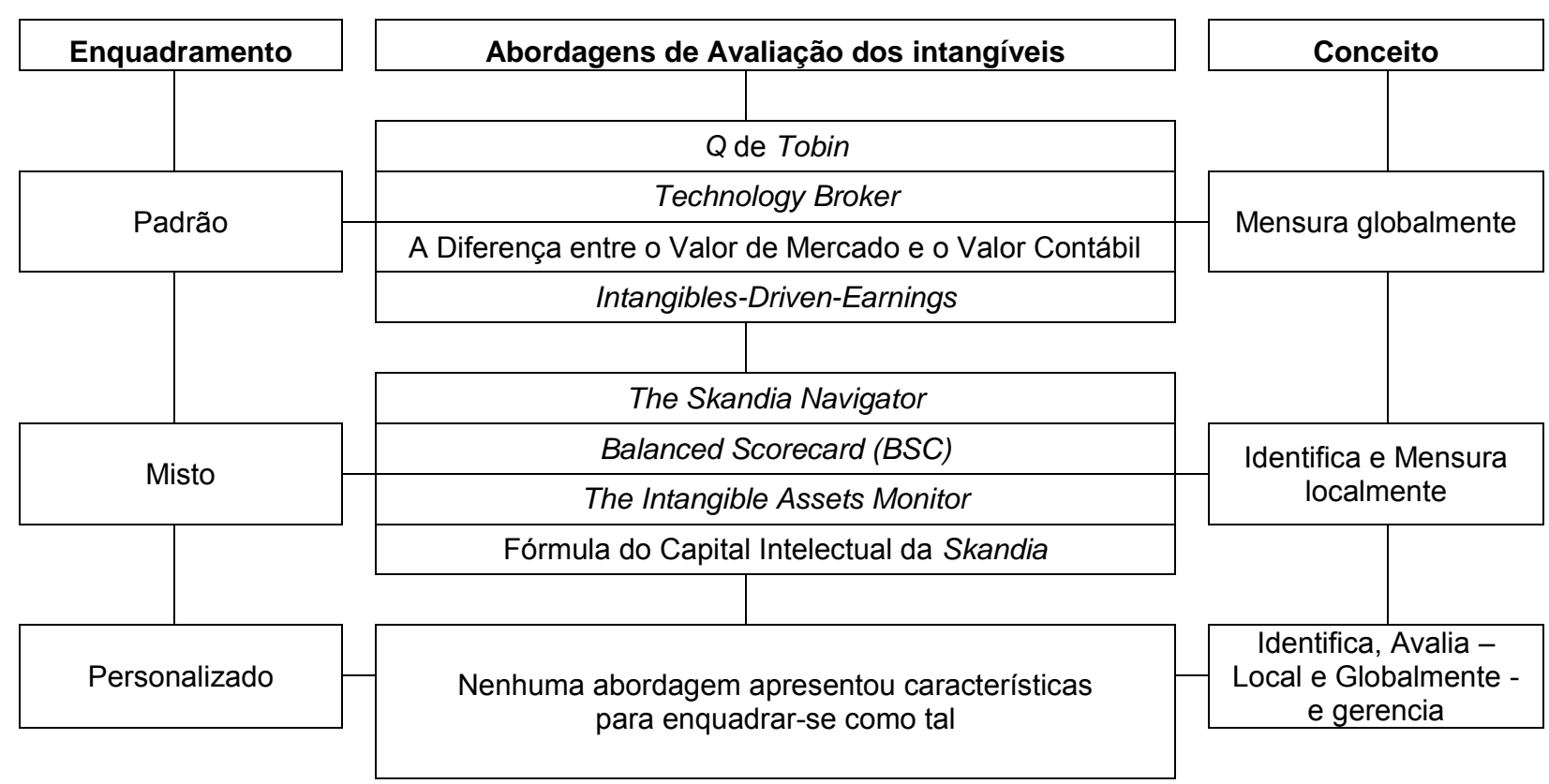

Figura 4. Enquadramento das abordagens de avaliação dos intangíveis

Fonte: dados da pesquisa.

Verificou-se, portanto, que 4 abordagens enquadraram-se como abordagem padrão que mensura globalmente. Apresentam uma estrutura julgada válida para todas as situações e empresas e buscam identificar um valor global para os ativos intangíveis, sem identificar os itens que o compõem.

Já as demais abordagens, representadas também no total de 4 enquadraram-se como mista, que identifica e mensura localmente. Buscam estabelecer alguns padrões e também reconhecem que devem existir adaptações para cada situação e conhecer quais são os intangíveis de uma organização, além de conhecer seu desempenho localmente.

Percebe-se, no entanto, que nenhuma das abordagens apresentadas frequentemente na literatura nacional e internacional enquadraram-se como sendo personalizadas e que identificam, avaliam - local e globalmente - e gerenciam. Abordagens classificadas nesse enquadramento buscam cobrir todo o processo, indo desde a identificação dos ativos intangíveis, passando pela avaliação local e global, fechando o ciclo com o seu gerenciamento.

Observa-se, portanto, que as abordagens citadas na literatura não conseguem cobrir todo o processo, ou seja, identificar os ativos intangíveis, avaliar local e globalmente, para então, gerenciá-los.

Diante desse achado sugere-se que novas pesquisas trabalhem no desenvolvimento de abordagens de avaliação de intangíveis que possam atender a essa necessidade de enquadramento personalizado. Sugere-se também o levantamento das abordagens de avaliação de intangíveis utilizadas pelas empresas identificando o enquadramento e as categorias. 


\section{CONCLUSÕES}

$\mathrm{Na}$ era da informação e do conhecimento os ativos intangíveis são destacados como fonte de vantagem competitiva nas empresas, porém, é necessária efetiva gestão e aplicação desses ativos na sua conversão em resultados. Este trabalho teve por objetivo analisar as abordagens de avaliação dos ativos intangíveis por meio da literatura nacional e internacional.

Com base em um PB executou-se a identificação das abordagens de avaliação de ativos intangíveis mais citadas, classificando-as quanto às suas categorias e enquadramento. Identificou-se, portanto, que Skandia Navigator é a abordagem que mais se destaca nas pesquisas nacionais e internacionais. Na sequência, as abordagens (i) Balanced Scorecard; (ii) Intangible Assets Monitor, (iii) Q de Tobin; (iv) Tecnology Broker, (v) a Diferença entre o Valor de Mercado e o Valor Contábil; (vi) Fórmula do Capital Intelectual da Skandia e (vii) IntangiblesDriven-Earnings também foram destaque. Observou-se que as abordagens mais citadas foram criadas nos anos de 1990, validando a preocupação da época em desenvolver abordagens que auxiliassem a efetiva gestão desses ativos.

No entanto, observou-se que as abordagens mais citadas na literatura não se baseiam nas demonstrações contábeis. Nenhuma abordagem se enquadrou na categoria de Avaliação do Retorno dos Ativos, que possui como vantagem competitiva a facilidade de obtenção e compreensão entre os técnicos do meio econômico-financeiro, por serem baseadas nas demonstrações contábeis tradicionais.

Constatou-se também que as abordagens mais citadas não conseguem cobrir todo o processo, ou seja, não conseguem ir desde a identificação dos ativos intangíveis, passando pela avaliação local e global, fechando o ciclo com o seu gerenciamento. Não auxiliam, portanto, em uma efetiva gestão e aplicação de intangíveis, no auxílio de sua conversão em resultados.

Como limitações deste trabalho, apresenta-se que a pesquisa bibliográfica foi desenvolvida apenas com artigos publicados em periódicos disponíveis gratuitamente em algumas bases nacionais e internacionais.

A partir dessa análise, sugere-se, para futuras pesquisas, as constatações na prática da utilização das abordagens de avaliação de ativos intangíveis, identificando se tais abordagens estão sendo utilizadas de acordo com suas respectivas categorias e enquadramento. Sugerese, também, uma análise com o olhar tanto para ativos quanto para passivos intangíveis e o desenvolvimento de abordagens de avaliação de intangíveis que possam atender ao enquadramento personalizado.

\section{REFERÊNCIAS}

Antunes, M. T. P. (2006). A Controladoria e o Capital Intelectual: um estudo empírico sobre sua gestão. Revista Contabilidade \& Finanças - USP, 17(41).

Antunes, M. T. P., \& Martins, E. (2002). Capital intelectual: verdades e mitos. Revista Contabilidade \& Finanças - USP, 13(29).

Antunes, M. T. P., \& Martins, E. (2007). Capital intelectual: seu entendimento e seus impactos no desempenho de grandes empresas brasileiras. BASE - Revista de Administração e Contabilidade da UNISINOS, 4(1).

Barbosa, J. G. P., \& Gomes, J. S. (2002). Um estudo exploratório do controle gerencial de ativos e recursos intangíveis em empresas brasileiras. Revista de Administração Contemporânea, 6(2).

Boedker, C., Guthrie, J., \& Cuganesan, S. (2005). An integrated framework for visualising intellectual capital. Journal of Intellectual Capital, 6(4), 510-527.

Carvalho, F. N. de, \& Ensslin, S. R. (2006). A evidenciação voluntária do Capital Intelectual: um estudo revisionista do contexto internacional. Contabilidade Vista \& Revista, 17(4). 
Ensslin, S. R., Ensslin, L., Kremer, A. W., Chaves, L. C. \& Borgert, A. (2014). Comportamentos dos custos: seleção de referencial teórico e análise bibliométrica. Revista de Contabilidade do Mestrado de Ciências Contábeis da UERJ. 19(3).

Francini, W. S. (2002). A gestão do conhecimento: conectando estratégia e valor para a empresa. RAE-eletrônica, 1(2).

Gallon, A. V., Souza, F. C. de, Rover, S., \& Ensslin, S. R. (2008). Um estudo reflexivo da produção científica em capital intelectual. Revista de Administração Mackenzie, 9(4).

García-Meca, E., \& Martínez, I. (2007). The use of intellectual capital information in investment decisions: An empirical study using analyst reports. The International Journal of Accounting, 42(1), 57-81.

Gil, A. C. (2008). Métodos e Técnicas de Pesquisa Social. (6a ed.). São Paulo: Atlas.

Hidalgo, R. L., García-Meca, E., \& Martínez, I. (2011). Corporate governance and intellectual capital disclosure. Journal of Business Ethics, 100(3), 483-495.

Jacobsen, K., Hofman-Bang, P., \& Nordby Jr, R. (2005). The IC Rating ${ }^{\text {TM }}$ model by Intellectual Capital Sweden. Journal of Intellectual Capital, 6(4), 570-587.

Joia, L. A. (2001). Medindo o capital intelectual. Revista de Administração de Empresas, 41(2).

Kang, H. H., \& Gray, S. J. (2011). Reporting intangible assets: Voluntary disclosure practices of top emerging market companies. The international journal of accounting, 46(4), 402-423.

Kannan, G., \& Aulbur, W. G. (2004). Intellectual capital: Measurement effectiveness. Journal of Intellectual Capital, 5(3), 389-413.

Kayo, E. K., Kimura, H., Basso, L. F. C., \& Krauter, E. (2006). Os fatores determinantes da intangibilidade. Revista de Administração Mackenzie, São Paulo, 7(3), 112-130.

Kim, D., \& Kumar, V. (2009) A framework for prioritization of intellectual capital indicators in R\&D. Journal of Intellectual Capital, 10(2), 277-293.

Leitner, K. (2005). Managing and reporting intangible assets in research technology organisations. $R$ and D Management, 35(2).

Kumar, G. (2013). Voluntary disclosures of intangibles information by US-listed Asian companies. Journal of International Accounting, Auditing and Taxation, 22(2), 109-118.

Leitner, K. \& Warden, C. (2004). Managing and reporting knowledge-based resources and processes in research organizations: specifics, lessons learned and perspectives. Management Accounting Research, 15(1), 33-51.

Lev, B. (2001) Intangibles: Management, measurement, and reporting. Brookings Institution Press, Washington, D.C.

Lev, B., \& Daum, J. H. (2004). The dominance of intangible assets: consequences for enterprise management and corporate reporting. Measuring Business Excellence, 8(1), 617.

Lima, A. C., \& Carmona, C. U. (2011). Determinantes da formação do Capital Intelectual nas empresas produtoras de Tecnologia da Informação e Comunicação. Revista de Administração Mackenzie, 12(1).

Macagnan, C. B. (2009). Voluntary disclosure of intangible resources and stock profitability. Intangible Capital, 5(1).

Macagnan, C. B., \& Fontana, F. B. (2013). Factors explaining the level of voluntary human capital disclosure in the Brazilian capital market. Intangible Capital.

Manfred, B., \& Kay, A. (2007). The German guideline for intellectual capital reporting: method and experiences. Journal of Intellectual Capital, 8(4), 563-576. 
Oliveira, J. M. de, \& Beuren, I. M. (2003). O tratamento contábil do capital intelectual em empresas com valor de mercado superior ao valor contábil. Revista Contabilidade \& Finanças - USP, 14(32).

Oliveira, L., Rodrigues, L. L., \& Craig, R. (2006). Firm-specific determinants of intangibles reporting: evidence from the Portuguese stock market. Journal of Human Resource Costing \& Accounting, 10(1), 11-33.

Oliveira, L., Rodrigues, L. L. \& Craig, R. (2010). Intellectual capital reporting in sustainability reports. Journal of Intellectual Capital, 11(4), 575-594.

Ortiz, M. A. A. (2009). Analysis and Valuation of Intellectual Capital According to Its Contex. Journal of Intellectual Capital, 10(3), 451-482.

Pablos, P. O. de. (2003). Intellectual capital reporting in Spain: a comparative view. Journal of Intellectual Capital, 4(1).

Perez; M. M., \& Famá, R. (2006). Ativos intangíveis e o desempenho empresarial. Revista Contabilidade \& Finanças - USP, (40), 7-24.

Ramirez, Y. (2010). Intellectual capital models in Spanish public sector. Journal of Intellectual Capital, 11(2), 248-264.

Roos, G., \& Roos, J. (1997). Measuring your company's intellectual performance. Long Range Planning, 30(3), 413-426.

Santos, J. L. (2002). Ativos intangíveis. ConTexto, Porto Alegre, 2(2), 1-14.

Santos, J. L., \& Schmidt, P. (2003). Ativos intangíveis: análise das principais alterações introduzidas pelos FAS 141 e 142. ConTexto, Porto Alegre, 3(4), 1-18.

Seetharaman, A., Low, K. T., \& Saravanan, A. S. (2004). Comparative justification on intellectual capital. Journal of Intellectual Capital, 5(4), 522-539.

Schnorrenberger, D. (2005). Identificando e avaliando os ativos intangíveis de uma organização visando seu gerenciamento: uma ilustração na área econômico-financeira. Tese de doutorado, Universidade Federal de Santa Catarina, Florianópolis, SC, Brasil.

Sveiby, K. E. (1997). The Intangible Assets Monitor. Journal of Human Resource Costing \& Accounting, 2(1), 73-97.

Sveiby, K. E. (2001). Methods for Measuring Intangible Assets. Recuperado em 01 de julho, 2016, de http://www.sveiby.com/articles/IntangibleMethods.htm.

Teh, C. C., Kayo, E. K., \& Kimura, H. (2008). Marcas, patentes e criação de valor. Revista de Administração Mackenzie, 9(1).

Usoff, C. A., Thibodeau, J. C., \& Burnaby, P. (2002). The importance of intellectual capital and its effect on performance measurement systems. Managerial Auditing Journal, 17(1/2), 915.

Vergauwen, P. G., \& Van Alem, F. JC. (2005). Annual report IC disclosures in the Netherlands, France and Germany. Journal of Intellectual Capital, 6(1), 89-104.

Wernke, R., \& Bornia, A. C. (2003). Estudo de caso aplicando modelo para identificação de potenciais geradores de intangíveis. Revista Contabilidade \& Finanças, São Paulo, 14(33), 45-64.

Zéghal, D., \& Maaloul, A. (2011). The accounting treatment of intangibles - A critical review of the literature. Accounting Forum, 35(4), 262-274. 